\title{
An outpatient multidisciplinary pulmonary rehabilitation programme was effective in disabling chronic lung disease
}

Griffiths TL, Burr ML, Campbell IA, et al. Results at 1 year of outpatient multidisciplinary pulmonary rehabilitation: a randomised controlled trial. Lancet 2000 Jan 29;355:362-8.

QUESTION: What is the effectiveness of an outpatient multidisciplinary pulmonary rehabilitation programme in patients with disabling chronic lung disease?

Design

Randomised (allocation concealed*), unblinded,* controlled trial with 1 year follow up.

\section{Setting}

A teaching and district general hospital in Penarth, Wales, UK.

\section{Patients}

200 patients (mean age 68 y, 60\% men) with disabling chronic lung disease $(84 \%$ with chronic obstructive lung disease) who had an $\mathrm{FEV}_{1}<60 \%$ of the predicted normal rate with $<20 \%$ reversibility in response to an inhaled $\beta$-agonist. Patients were excluded if they could not walk, had severe sensory or cognitive impairment, or had symptomatic ischaemic heart disease. Follow up was $90 \%$.

\section{Intervention}

After stratification by sex and primary nature of lung disease (obstructive or non-obstructive), patients were allocated to a 6 week multidisciplinary pulmonary rehabilitation programme (rehabilitation group, $n=99$ ) or to standard medical management (control group, $\mathrm{n}=101$ ). The rehabilitation programme used services from occupational therapists, physiotherapists, dietitians, respiratory nurses, and smoking cessation counsellors. It consisted of 18 visits (lasting about $2 \mathrm{~h}$ each) that involved exercise and education on pulmonary disease, nutrition, stress management, and medications. At the end of the programme, patients were invited to join a patient run group for social activities and exercise.

\section{Main outcome measures}

Use of health services, walking ability, and general and disease specific health status.

Source of funding: Wales Office of Research and

Development for Health and Social Care.

For correspondence: Dr T L Griffiths,

Section of Respiratory Medicine, Department of Medicine, University of Wales College of Medicine, Llandough Hospital, Penarth

CF64 2XX, Wales, UK

Fax $+44(0) 2920$

712284.

\section{Main results}

Analysis was by intention to treat. Of the patients who group had lower mean numbers of admissions (1.7 $v 2.2$, $\mathrm{p}=0.048)$ and days spent in the hospital (10.4 v 21.0, $\mathrm{p}=0.022)$ than those in the control group. Patients in the rehabilitation group had a higher mean number of consultations at the general practitioner's office (8.6 v $7.3, \mathrm{p}=0.033)$ and a lower mean number of general practitioner home visits $(1.5 v 2.8, \mathrm{p}=0.037)$ than those in the control group. Patients in the rehabilitation group showed greater improvement in walking ability $(p=0.002)$ and general and disease specific health status were admitted to hospital, those in the rehabilitation $(\mathrm{p}<0.05)$ than those in the control group. Rehabilitation and control groups did not differ for the numbers of patients admitted to the hospital (40 $v 41, \mathrm{p}=0.98$ ).

\section{Conclusion}

An outpatient multidisciplinary pulmonary rehabilitation programme decreased the use of health services and improved the general and disease specific health status of patients with disabling chronic lung disease.

*See glossary.

\section{COMMENTARY}

In recent years, numerous clinical trials have been done to study the effects of pulmonary rehabilitation. The findings of Griffiths $e t a l$ are consistent with those from previous studies. For example, a recent study by Guell $e$ t al found long term benefits with outpatient rehabilitation. ${ }^{1}$ A salient contrast between these 2 studies was that Guell $e$ et als programme did not emphasise patient education, whereas Griffiths and colleagues' programme devoted one third of the time to education. However, studies that tested the effects of educational interventions for pulmonary rehabilitation have not found benefits. ${ }^{23}$

Griffiths et al did a methodologically sound trial that provides additional support for pulmonary rehabilitation as an effective clinical intervention for chronic obstructive pulmonary disease. The programme was outpatient based, so the cost should be lower than that of inpatient programmes. The authors intend to follow up with an economic analysis of this trial, which will add further important information. Although long term benefits were found, the differences between control and intervention groups diminished over the 1 year interval. In view of this finding, studies that examine strategies for prolonging the benefits of pulmonary rehabilitation are warranted. Finally, because educational interventions have shown no measurable benefits, researchers should scrutinise the design of educational intervention studies. Inadequate instructional design could have caused the lack of effect of educational interventions.

Arthur Jones, EdD, RRT

University of Texas Health Science Center at San Antonio San Antonio, Texas, USA

1 Guell R, Casan P, Belda J, et al. Long-term effects of outpatient rehabilitation of COPD: a randomized trial. Chest 2000;117:976-83.

2 Sassi-Dambron DE, Eakin EG, Ries AL, et al Treatment of dyspnea in COPD. A controlled clinical trial of dyspnea management strategies. Chest 1995;107:724-9.

3 Blake RL Jr, Vandiver TA, Braun S, et al. A randomized controlled evaluation of a psychosocial intervention in adults with chronic lung disease. Fam Med 1990;22:365-70. 